\title{
The Impact of Chagas Disease Control in Latin America - A Review
}

\author{
JCP Dias $/{ }^{+}$, AC Silveira* ${ }^{*}$ CJ Schofield** \\ Centro de Pesquisas René Rachou-Fiocruz, Av. Augusto de Lima 1715, 30190-002 Belo Horizonte, MG, Brasil \\ *PAHO, Brasília, DF, Brasil **ECLAT/LSHTM, London, UK
}

\begin{abstract}
Discovered in 1909, Chagas disease was progressively shown to be widespread throughout Latin America, affecting millions of rural people with a high impact on morbidity and mortality. With no vaccine or specific treatment available for large-scale public health interventions, the main control strategy relies on prevention of transmission, principally by eliminating the domestic insect vectors and control of transmission by blood transfusion. Vector control activities began in the 1940s, initially by means of housing improvement and then through insecticide spraying following successful field trials in Brazil (Bambui Research Centre), with similar results soon reproduced in São Paulo, Argentina, Venezuela and Chile. But national control programmes only began to be implemented after the 1970s, when technical questions were overcome and the scientific demonstration of the high social impact of Chagas disease was used to encourage political determination in favour of national campaigns (mainly in Brazil). Similarly, large-scale screening of infected blood donors in Latin America only began in the 1980s following the emergence of AIDS.

By the end of the last century it became clear that continuous control in contiguous endemic areas could lead to the elimination of the most highly domestic vector populations - especially Triatoma infestans and Rhodnius prolixus - as well as substantial reductions of other widespread species such as $\mathrm{T}$. brasiliensis, T. sordida, and $\mathrm{T}$. dimidiata, leading in turn to interruption of disease transmission to rural people. The social impact of Chagas disease control can now be readily demonstrated by the disappearance of acute cases and of new infections in younger age groups, as well as progressive reductions of mortality and morbidity rates in controlled areas. In economic terms, the cost-benefit relationship between intervention (insecticide spraying, serology in blood banks) and the reduction of Chagas disease (in terms of medical and social care and improved productivity) is highly positive. Effective control of Chagas disease is now seen as an attainable goal that depends primarily on maintaining political will, so that the major constraints involve problems associated with the decentralisation of public health services and the progressive political disinterest in Chagas disease. Counterbalancing this are the political and technical cooperation strategies such as the "Southern Cone Initiative" launched in 1991. This international approach, coordinated by PAHO, has been highly successful, already reaching elimination of Chagas disease transmission in Uruguay, Chile, and large parts of Brazil and Argentina. The Southern Cone Initiative also helped to stimulate control campaigns in other countries of the region (Paraguay, Bolivia, Peru) which have also reached tangible regional successes. This model of international activity has been shown to be feasible and effective, with similar initiatives developed since 1997 in the Andean Region and in Central America. At present, Mexico and the Amazon Region remain as the next major challenges. With consolidation of operational programmes in all endemic countries, the future focus will be on epidemiological surveillance and care of those people already infected. In political terms, the control of Chagas disease in Latin America can be considered, so far, as a victory for international scientific cooperation, but will require continuing political commitment for sustained success.
\end{abstract}

Key words: Chagas disease - vector control- Southern Cone Initiative - Latin America

Over the last 10 years, a series of multinational initiatives has led to significant reductions in the social and economic impact of Chagas disease in the Americas. By the early 1990s, Chagas disease was ranked by the World Bank as the most serious of the parasitic diseases in Latin America, with a socioeconomic impact (measured as DALYs - Disability-Adjusted Life Years) considerably greater than that of the combined effects of all other parasitic infections (World Bank 1993). The number of people

${ }^{+}$Corresponding author. Fax: +55-31-3295.3115. E-mail: jcpdias@cpqrr.fiocruz.br

Received 20 May 2002

Accepted 19 June 2002 infected was estimated at 16-18 million, with a further 100 million considered at risk (WHO 1991). Now the estimates of infection prevalence are being progressively revised downwards, to a current figure of just over 11 million (Schmunis 1999a). Most of this success is due to largescale regional initiatives to halt vector-borne transmission, together with improved screening of blood-donors to reduce the likelihood of transfusional transmission, and improved detection and treatment of congenital cases. In many areas this has also been paralleled by human migrations from endemic rural areas to cities where the likelihood of vector-borne transmission is generally low.

It is a mistake, however, to imagine that Chagas disease is conquered. High levels of vector-borne transmission are still apparent in many areas, and several of the endemic countries have yet to develop serious large-scale 
surveillance and intervention programmes. Even in areas where transmission has now been declared essentially zero, there is a continuing risk of recrudescence of vector-borne transmission due to premature curtailing of entomological surveillance and vigilance activities. Moreover, transmission is clearly increasing in newly colonised areas such as the Amazon basin, and the ever-increasing movements of human populations offer a perenniel risk of new transmission in previously non-endemic regions including areas outside Latin America. Our aim in this review is to examine key events and technical developments that have favoured Chagas disease control in the Americas, with a view to clarifying the misconceptions that can prejudice successful continuation of these activities. The most serious of these can lead to misdirected policy, threatening to loose many of the benefits so far gained and impeding the realistic objective of liberating Latin American communities from this chronic and debilitating disease.

\section{PROGRESS OF CHAGAS DISEASE VECTOR CONTROL}

Attempts to control Chagas disease began soon after Carlos Chagas' outstanding studies in the first decades of the last century. No treatment was then available for human infections, and prior to World War II there were few suitable techniques for controlling the domestic insect vectors. Attempts were made to control Panstrongylus megistus in Brazil using kerosene or boiling water thrown over the walls of infested houses, and there were some limited trials with military flame-throwers. Isolating the house with a canvas cover and injecting cyanide gas was more effective, although quite impractical on a large scale. But Chagas also recognised the importance of improved living conditions to control domestic Triatominae. He reasoned that since the bugs lived in cracks and crevices in house walls, then improved structures should provide fewer resting places for the bugs. Under his leadership and that of his colleagues such as José Pellegrino and Emmanuel Dias, several experiments were made in rural housing improvement, which today remains an important element of Chagas disease control.

The advent of synthetic insecticides during the 1940s was the first major breakthrough in techniques for Chagas disease vector control. DDT was quickly found to be ineffective against $P$. megistus and Triatoma infestans, and with only a latent effect against Rhodnius prolixus. But two other organochlorines, dieldrin and gamma-BHC (also known as $\mathrm{HCH}$, lindane, gammexane), were found to be highly effective when sprayed over house walls at relatively high doses (Romaña \& Abalos 1948, Dias \& Pellegrino 1948). For many years BHC remained the mainstay of Chagas disease vector control trials and campaigns, although dieldrin was more widely used in trials in Venezuela since 1957, and during their national campaign against $R$. prolixus formally initiated in 1966 . The Venezuelan campaign was the first large-scale programme against Chagas disease vectors, and acheived impressive results. By 1976, evaluation of 382,071 rural houses in the six most highly affected states (Aragua, Carabobo, Cojedes, Portuguesa, Trujillo, Yaracuy) indicated that the proportion infested (house infestation rate) had been reduced from $31.1 \%$ to $5.6 \%$. Similarly, overall seropositiv- ity of the rural population declined from $44.4 \%$ in the 19591963 survey, to $11.7 \%$ in 1980-1984. Seropositivity in children $0-9$ years old declined from $20.5 \%$ to $1.5 \%$, indicating a substantial reduction in active transmission.

During the 1950s-1970s, most classes of synthetic insecticide were trialed against Chagas disease vectors, as they became available. But none showed significant advantages over $\mathrm{BHC}$ or dieldrin, and most were more expensive. The early 1980s however, saw the launch of synthetic pyrethroid insecticides, which were to prove a major technical breakthrough. Comparative trials in Brazil and elsewhere soon established that the new compounds were considerably more effective than BHC in eliminating domestic bug infestations, even at very low doses, and even when applied just once. The new compounds were considerably more expensive (per kilo) than BHC, but because of the low doses, ease of use, and infrequent applications, they were more cost-effective. Moreover, they left no unpleasant smell, did not mark the treated house walls, and so were more readily accepted both by spraymen and householders.

With the accumulating operational experience in Chagas disease vector control - especially in Venezuela and the Brazilian State of São Paulo - together with compelling studies on the pathology and social impact of the disease, particularly for chronically infected cardiopathic cases, the stage was set for launching the first Brazilian national campaign in 1983 (Dias 1987). This was a truly national campaign, including amongst its objectives the complete eradication of the main vector, $T$. infestans, from national territory. It was designed to cover all the endemic states with a comprehensive mapping of infested localities, and spraying of infested houses - initially with BHC but progressively replaced with synthetic pyrethroids. And once sprayed, a system of community-based vigilance was set up, whereby householders could report the finding of bugs to a local volunteer post (known as PIT - Posto de Informação sobre Triatomíneos). The public health inspectors would periodically visit the PITs, confirm the presence of bugs, and organise selective respraying where necessary.

The 1983 Brazilian campaign was ably planned and executed by staff of Sucam (at that time, the executive arm of the Ministry of Health). By 1986, almost $75 \%$ of the geographic objectives had been attained, in the sense that infested localities had been mapped, sprayed, and placed under community-based vigilance. But in 1986, the epidemiological situation changed drastically with the return of Aedes aegypti to Brazilan coastal cities. Ae. aegypti is the urban vector of yellow fever, which had been successfully eliminated from most of South America by the 1960s. Its return in the 1980s brought with it not just the threat of renewed yellow fever transmission, but also epidemics of dengue. Uncomplicated dengue is far from life-threatening, and even dengue haemorrhagic fever or shock syndrome can usually be successfully treated. But dengue affects urban populations, including journalists. There was public and political alarm, and the rural Chagas disease campaign became subordinate to a new urban Ae. aegypti campaign.

By 1990 it was becoming clear that the problem for Chagas disease vector control rested less with technical 
questions, and more with political decision. Only five countries of the Americas had official programmes against Chagas disease, and none of these had fully prioritised objectives. There was also an obvious biological problem. As with other insect pests, Triatominae are no respecters of national borders, and can be readily transported from untreated to treated areas - especially amongst the belongings of visitors. This had already been recognised in the Brazilian campaign of 1983-1986 when Brazil made frontier agreements with neighbouring Paraguay and Uruguay for control of $T$. infestans on the other side of their border.

The enlightened response to both problems - political and biological - came in the form of the Southern Cone Initiative. This was a joint agreement, signed in 1991, between the governments of Argentina, Bolivia, Brazil, Chile, Paraguay, Uruguay, and later Peru, to control Chagas disease by the elimination of the main vector, $T$. infestans. These seven countries encompass the entire geographic distribution of T. infestans, which was recognised to have originated in central Bolivia but to have been transported in association with human migrations to other countries (Schofield 1988, Dujardin et al. 1998a). Throughout its distribution, it appeared to be exclusively domestic or peridomestic, with no silvatic populations except in parts of central Bolivia. However, genetic studies had indicated incipient speciation and a lack of gene flow between the silvatic populations and neighbouring domestic populations in central Bolivia (Dujardin et al. 1996, 1997a,b, 1998a) so that the idea of complete elimination of all domestic and peridomestic populations of $T$. infestans seemed biologically feasible as well as politically acceptable.

The underlying rationale behind the Southern Cone Initiative was the idea that international agreement would favour the continuity of national policy for Chagas disease control, while the common objectives would reduce the risk of accidental cross-border carriage of the vectors, or of infected blood products. The primary objective of eliminating $T$. infestans included the idea of suppressing or controlling populations of other species that might be of local importance. The second objective was to reduce the risk of Chagas disease transmission by blood transfusion. In general, each country within the initiative finances its national activities, and retains complete autonomy for programme implementation. Operational aims, methods, and achievements, are discussed annually at the meeting of the Southern Cone Commission coordinated by the Pan American Health Organization (PAHO).

A preliminary analysis of likely costs and benefits of the Southern Cone programme predicted that total costs over a 10 year period (1991-2000) would be between US $\$ 190$ million and US\$350 million, but against this, direct benefits from savings in medical costs alone would sum to around US $\$ 53$ million per year, with an estimated annual rate of return on investment of just over 14\% (Schofield \& Dias 1991). To date (1991-2001), the combined investment of the seven governments is estimated at just over US $\$ 320$ million. Point studies that include benefits from reduced morbidity as well as savings in medical costs, indicate actual rates of financial return of around $30 \%$ in Brazil (Akhavan 2000) and over 64\% in Argentina (Basombrio et al. 1998). The detailed analysis by Akhavan
(2000) shows that in the period 1975 to 1995 , the government of Brazil had invested just over US\$420 million in Chagas disease control, with consequent benefits of well over US $\$ 3$ billion - a return of US $\$ 7.16$ for every dollar invested.

The Southern Cone Initiative has been highly successful, as shown by the current rarity of T. infestans over much of its previous distribution, and by the sharp decline in the infection rates of children born since the programme began (Schmunis 1999b, Schofield \& Dias 1999). Uruguay and Chile were formally certified free of human Chagas disease transmission in 1997 and 1999 respectively, and six of the previously endemic states of Brazil were similarly certified in March 2000 (Goiás, Mato Grosso, Mato Grosso do Sul, Paraíba, Rio de Janeiro, São Paulo), with the State of Minas Gerais also certified in March 2001. In practical terms, this means that even the poorest rural families in these regions, living in even the poorest conditions, can live in houses free of domestic Triatominae, free of the risk of Trypanosoma cruzi infection. In addition, because of stringent efforts to improve the screening of blood donors, the supply of blood and blood products has become much safer throughout the Southern Cone region. Moreover, epidemiological data are indicating some unexpected clinical benefits as improvements in disease progression amongst those people already infected before the control programme, together with a reduced likelihood that infected mothers will pass the infection to their offspring by transplacental transmission. The reasons for this are not clear, but may relate to the absence of reinfection as a result of the vector control interventions.

Stimulated by the Southern Cone success against $T$. infestans, two further regional initiatives were launched in 1997 - in Central America, and in the Andean pact region. In both cases, the main targets are $R$. prolixus and $T$. dimidiata (together with $R$. pallescens in Panama, and R. ecuadoriensis in Northern Peru). R. prolixus has a discontinuous geographical distribution, from Venezuela and Colombia, and the central part of Central America. But it has never been recorded from Northwestern Colombia, nor from Panama or Southern Costa Rica, and it was quickly eliminated from Northern Costa Rica by insecticide spraying in the early 1950s (Ruiz 1953). Historical reconstruction backed by genetic and morphometric comparisons indicates that $R$. prolixus was accidentally imported to Central America just prior to 1915 and, like T. infestans in the Southern Cone, it appears to have been spread as a domestic species in association with human migrations (Schofield \& Dujardin 1997, Dujardin et al. 1998b). There is also some evidence that $R$. prolixus was spread by humans from Venezuela into the central Magdalena valley of Colombia (Schofield \& Dujardin 1999). As far as is known, no silvatic populations of $R$. prolixus occur either in Central America or in central Colombia, so that in both regions this domestic species is considered a feasible candidate for complete elimination. By contrast, $T$. dimidiata has many silvatic ecotopes in Southern Mexico and Central America, although silvatic specimens have only rarely been reported from Colombia, and not at all from Ecuador. Current genetic studies suggest that $T$. dimidiata may have originated in the Yucatan region, fol- 
lowed by a natural spread North and South, so that there is some evidence of clinal variation as far South as Panama (Solis-Mena et al. 2000, Marcilla et al. 2001, Schofield 2002). But Ecuadorian populations of T. dimidiata show close genetic similarities with those of Southern Mexico (SolisMena et al. 2000, Abad-Franch et al. 2001) suggesting that they may have been transported to Ecuador along precolombian maritime routes which are well established by archaeological evidence (Meggers \& Evans 1963).

Based on these various studies, the current operational appraisal is that $R$. prolixus is a feasible candidate for eradication from Central America and possibly also from central Colombia, while T. dimidiata may be a feasible candidate for eradication from Ecuador and Northern Peru. R. ecuadoriensis may also be a feasible candidate for eradication from Northern Peru, where the first control trials are currently underway (F Vargas et al., unpublished ECLAT report). Similarly, evidence from control trials in Mexico suggest that T. barberi may be a candidate for eradication (Ramsey et al. 2000) although widespread species of the phyllosoma complex, such as $T$. pallidipennis, may require a more long term control approach similar to that proposed for $T$. dimidiata in Central America (Acevedo et al. 2000).

\section{MEDICAL AND SOCIAL IMPACT OF CHAGAS DISEASE CONTROL}

Countries or regions under effective and continuous vector control activities have seen a significant decline in the the incidence of human Chagas disease, accompanied by reductions in disease prevalence. In all cases, significant reductions in the rates of house infestation by domestic Triatominae have been accompanied by a rapid reduction in the frequency of apparent acute cases - as had been well documented from previous studies in Bambuí, Minas Gerais (Dias 1982) and in the State of São Paulo (Souza et al. 1984). As an immediate consequence, age-specific prevalence curves become displaced to reflect the reduction in new cases amongst younger agegroups (Dias 1982, 2000). This primary impact of vector control is easily recognised when endemic areas are sprayed. For Uruguay, where the overall index of house infestation by T. infestans decreased from 6\% in 1983 to $0.3 \%$ in 1996 , the infection rate in 6-12 year old children was reduced from $2.4 \%$ in 1985 to $0.1 \%$ in 1996 . For Chile in the same period, house infestation was reduced from $20 \%$ to $0.1 \%$ and childhood infection from $7.2 \%$ to $0.1 \%$. Similar pictures are being observed in other countries of the Southern Cone Initiative, such as Brazil and extensive areas of Argentina, Paraguay, and Southern Bolivia (Tupiza region) (Vinhaes 2002). In parallel, vector control is also associated with a marked reduction in rates of transmission by secondary mechanisms such as transfusional transmission from infected blood donors and congenital (transplacental) transmission from infected mothers. This is an expected reflection of the changes in age-specific prevalence, due to the declining prevalence in younger age-groups that leads to a progressive reduction in the number of infected blood donors and infected mothers (Wendell 1997, Dias \& Schofield 1999). Nevertheless, there is also a suggestion of declining likelihood of congenital transmission even amongst previously-infected mothers
- which may indicate a hitherto unsuspected benefit due to absence of reinfection (see below).

Clinical improvements - In clinical terms, chronic Chagas disease infections (i.e. infections initiated prior to the current vector control campaigns) are showing significant reductions in morbidity and premature mortality due to $T$. cruzi infection (Figs 1,2) - again suggesting a benefit due to the absence of reinfection. The first to note this was Emmanuel Dias who, in 1962, observed that the more severe cardiopathic lesions became less apparent amongst cohorts of chronic Chagas cases in Bambuí, about 5-6 years after a general insecticide spraying of the municipality. During the 1970s, a similar phenomenon was observed by Vanize Macedo in the municipality of São Felipe, Bahia, following local spraying campaigns against domestic P. megistus. Both these authors suggested that a reduction of reinfection, due to reductions in vector infestation rates, might be responsible for the declining morbidity amongst chronically infected individuals (Dias 1962, Macedo 1976). In recent studies, mainly in Brazil and Uruguay, it is not only a reduction in the incidence of chronic chagasic cardiopathy that is being observed following the vector control activities, but also a steady reduction in the number of hospital internments

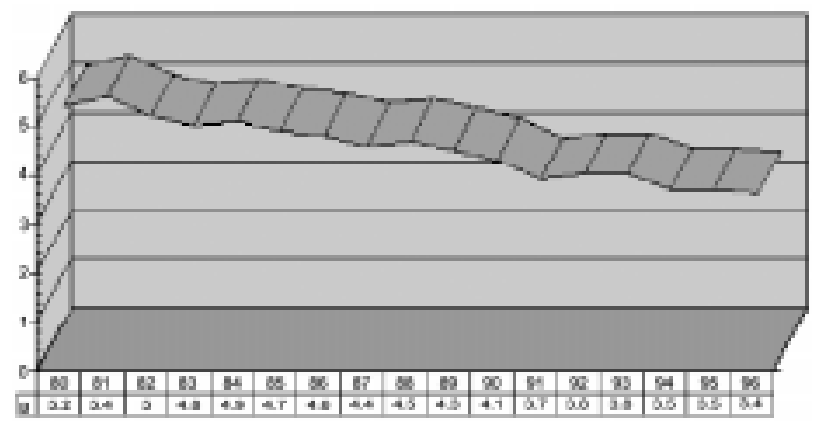

Source: Cenepi/Funasa, Ministry of Health

Fig. 1: annual mortality per 100,000 due to Chagas disease in Brazil, 1980-1996.

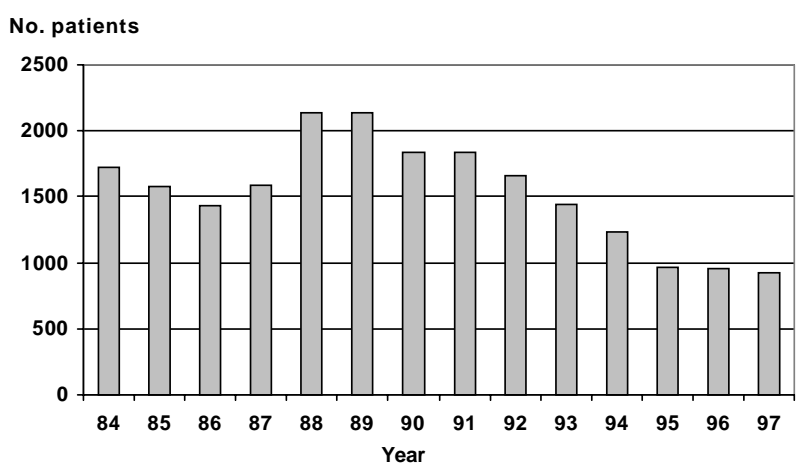

Fig. 2: annual number of hospital internments due to Chagas disease in Brazil, 1984-1997. Note how the number of hospitalisations declines in the period of the national vector control programme (1983-1986) then rises as this programme was suspended in response to the demand of new dengue epidemics. But from the launch of the new vector control interventions with the Southern Cone Initiative, in 1991, there has been a steady decline in the number of hospitalisations (data from Ministry of Health, Brasília, Brazil). 
and premature mortality due to chronic Chagas disease (Figs 1,2). Age-specific mortality due to chronic Chagas disease is moving from the classical 35-55 age range to age groups higher than 60 years (Dias 2000). Lack of reinfection due to successful elimination of the domestic vectors is one hypothesis to explain the more benign clinical pictures. Other possibilities could relate to improved and earlier access of patients to medical care and the social benefits provided by social security (Dias 1982). Another speculation is based on Koberle's theory, according to which the intensity of chronic disease is related to the intensity of the initial acute infection - which has declined in association with the vector control activities (Dias 1962, 2000).

Improved blood safety - Additional medical benefits of the Chagas disease control initiatives have accrued from improvements in the screening of blood donors, leading to greatly improved safety of blood and blood products throughout Latin America. The problem of tranfusional Chagas disease was suspected in 1935 and clearly defined in the 1940s. The basic tools and strategies to avoid transfusional transmission were developed in the 1950 s, but it was only in the 1980s, with the emergence of AIDS, that national and regional blood control programmes began to be fully implemented in the endemic countries (Wendel 1997, Dias \& Schofield 1998). The basic strategies for control of transfusional transmission involve serological selection of blood donors and chemoprophylaxis of suspect blood using trypanocidal drugs (WHO 1991, Wendel 1997). At the beginning of the Southern Cone Initiative, in 1991, transfusional transmission was still an important health problem throughout Latin America, with relatively few well-controlled blood banks in the endemic countries and only three countries (Argentina, Brazil and Uruguay) with national legislation regulating blood quality. The mean rate of the prevalence of chagasic donors in blood banks ranged from $0.15 \%$ in Ecuador to more than $40 \%$ in Bolivia, with high levels of seroprevalence also in parts of Argentina, Paraguay and Chile. Significant levels of seroprevalence amongst blood donors were also shown in other countries, such as Venezuela (4\%) and Guatemala (8\%), with a likely extrapolation to other regions due to international migrations. For example, in 1991 the prevalence of $T$. cruzi infection in Hispanic blood donors in the USA was $0.16 \%$, compared to zero amongst non-Hispanic donors (Wendel 1997).

One of the primary objectives of the Southern Cone Initiative was to provide expertise about transfusional control and to stimulate immediate revision of the problem in the different countries. There were several technical workshops, together with expert visits and supervision including update of epidemiological data and interchange of techniques, reference sera and reagents, with the establishment of reference laboratories in each endemic country (Dias \& Schofield 1998, Moraes-Souza 2000). Leading from this, almost all endemic countries of Latin America now have legislation regulating the screening of blood for transfusion, and the prevalence of $T$. cruzi infection amongst blood donors is rapidly decreasing in the great majority of the region (Moraes-Souza 2000, Schmunis et al. 2001). The degree of coverage of blood donor screening is also being increased, and now reaches almost $100 \%$ in Uruguay and parts of Brazil, also reaching high levels in Argentina, endemic part of Chile, Venezuela, Honduras and Paraguay (Schmunis et al. 2001). All this is aided by the successful vector control interventions leading to progressive reduction in the number of infected people entering the age for blood donation (Wendel 1997, Dias \& Schofield 1998).

Reductions in congenital transmission - Congenital (transplacental) transmission of T. cruzi had been known since studies in the 1940s, and has since been observed in most endemic countries. However, the likelihood that a chagasic mother would pass the infection to the foetus seems to vary between regions - generally ranging from 0.5 to $10 \%$ (WHO 1991, Dias \& Coura 1997, Bittencourt 2000). The direct preventive approach involves early diagnosis and specific treatment of infected new-borns, which depends on political and clinical awareness and an ambitious mother-child health programme. Within the Southern Cone Initiative, some countries (Uruguay, Paraguay and Argentina) have implemented a national routine by which every pregnant woman is serologicaly examined for $T$. cruzi infection, so providing diagnostic guidance at childbirth. But a problem remains in the low coverage of pre-delivery medical services in the majority of Latin American rural areas, as well as the difficulty of detecting congenital transmission without good parasitological methods, because current serological tests in new-borns only indicate antibodies passed from the mother (Bittencourt 2000). Because of this, the current trend amongst most public health programmes is to perform routine serology six months after the birth of children from chagasic mothers, with immediate treatment of seropositives. Most authorities are now in agreement with this policy, but the necessary diagnostic and clinical infrastructure is yet to be developed in many regions (Moya \& Moretti 1997, Dias \& Schofield 1999). For the future however, successful vector control can be expected to contribute to a marked reduction in congenital transmission, by reducing the likelihood of transmission to women of child-bearing age, and there are preliminary indications suggestive of a decline in the likelihood of congenital transmission - possibly due to a lack of reinfection of the infected mothers (Dias \& Coura 1997) (see above).

Social benefits - Yet to be fully researched is the full social impact of Chagas disease control in Latin America, although there are already many indications of direct social benefits, and several that can be expected. At the family level, one of the most emotive benefits is the absence of domestic triatomine bugs, which means that even the poorest of families can construct whatever kind of dwelling they may afford - without the nuisance of these blood-sucking insects, without the psychological stress that can result, and without the chronic blood loss associated with heavy infestations. Informal surveys have also indicated an improved sense of well-being, also shown by tangible evidence such as greater attempts at domestic tidiness and the planting of flowers around the house. Most importantly, as shown by studies in Venezuela (Briceño-León 1990, 1993), the vector control activities can lead to a greater sense of citizenship (rather than an oftenfelt sense of abandonment), which in turn can be expected to promote increased stability of rural communities. 
At the regional and international level, the Chagas disease control initiatives have, of necessity, promoted greater scientific and technical interchange, including a series of inter-country technical cooperation agreements developed by the Pan American Health Organisation offering opportunities for improved interaction between scientists, and between scientists and their respective government organisations. Since 1991, the Southern Cone Initiative rapidly showed valid results and helped the participant countries to improve and sustain their control programmes, helping to balance the trend towards governmental decentralization and the minimization of State structures. When the initiative began there were no formal programmes against Chagas disease in Bolivia, Paraguay, or Peru, and the initiation of national programmes in these countries - and subsequently in others through the Central American and Andean Pact initiatives - was a clear goal attained towards the end of the decade. By another standpoint, it has been argued that the Southern Cone Initiative served as an additional reinforcement to political and commercial cooperation in the region, such as the Mercosur pact, and has also become a model on which to base other large-scale disease control initiatives such as the recently launched Pan African Tsetse and Trypanosomiasis Eradication Campaign (PATTEC) launched by the Organisation of African Unity in 2000 (Schofield \& Maudlin 2001, Kabayo 2002). In terms of scientific cooperation, a series of collaborative international projects were developed in support of the control initiatives, including the ECLAT network (European Community and Latin American network for research on Triatominae) involving research groups in 22 countries, which has had a decisive influence on our understanding of the biology and evolution of domestic vectors of disease (Dias \& Schofield 1999, Schofield \& Dias 1999).

Most importantly perhaps, the success of the Chagas disease control initiatives in Latin America are offerring renewed confidence in our ability to mount large-scale campaigns against vector-borne diseases, not only from the successes achieved but also by demonstrating the validity of a large-scale approach emphasising inter-country cooperation. The success has been acknowledged by resolution of the World Health Assembly (WHO 1998) and, in addition to the Pan African initiative against African trypanosomiasis, other international initiatives aginst vector-borne diseases are being developed - most notably against malaria, lymphatic filariasis, and certain tickborne diseases (see also Ken-Hong 2000).

\section{CURRENT CONTROL INITIATIVES}

At the time of writing, control of Chagas disease is on the health policy agenda of all the endemic countries (except Guyana and French Guiana), and there are active programmes of Chagas disease vector surveillance and control in all except for Mexico, Costa Rica, Ecuador, Guyana and French Guiana. This is a major political achievement, flowing from the demonstrable success of large-scale campaigns particularly in Brazil and other Southern Cone countries, and is a tribute to the pioneering efforts of the research communities of these countries. And the political impact spreads well beyond the Americas, as the new paradigm of area-wide disease con- trol is taken up by campaigns against other vector-borne diseases such as lymphatic filariasis and African trypanosomiasis. Such campaigns have obvious social and medical benefits, protecting millions of people from preventable disease transmission, and the political impact is particularly important in restoring confidence in largescale intervention programmes. But the relationships between operational achievements and policy suffer from time-lags, so that the new paradigms of large-scale disease control often march out-of-step with the previous political paradigms of community-based approaches.

In the case of Chagas disease control, the historical appraisal reveals a series of operational stages that must be adapted to specific epidemiological situations within the context of differing national policies. The stages range from inactivity through various levels of survey and trial to large-scale campaigns, followed by consolidation and sustained vigilance. Each country of the Americas is at a different stage, facing a specific epidemiological pattern, so that translation of experience may not be immediately applicable. For example, the dedicated campaign approach of Sucam-Funasa that has been so successful against $T$. infestans in Central and Southern Brazil may be highly applicable to the elimination of $R$. prolixus in Central America, but would not be relevant to the situation in a country such as Suriname where transmission is due to adventitious silvatic vectors rather than domestic bug populations. And yet the Suriname approach to surveillance and control may be exactly what Brazil will require in the future - especially in the Amazon region.

What follows is our attempt to rationalise the stages in Chagas disease control, with our appraisal of the current position of each of the endemic countries. The stages are designed to follow a logical and ultimately successful sequence, leading to the elimination of Chagas disease as a public health problem. We believe the final stage represents a realistic and attainable goal, when there would be no more than occasional human infections resulting from adventitious contact with infected silvatic Triatominae. But equally, we believe that even the most successful programmes of today risk severe derailment, as discussed in the final section.

\section{STAGES IN CHAGAS DISEASE CONTROL}

\section{Stage 0. Inactivity}

The zero stage is represented by a lack of epidemiological data, or a national incapacity to acknowledge or investigate what data may exist. All endemic countries have begun at this stage, relying on their clinicians and research communities to reveal the existence of Chagas disease transmission, and the presence of feasible targets for national or regional control interventions. Most have now passed out of stage zero, since, with the exception of Guyana, there is now serological, clinical and entomological data from all countries of the Americas to allow at least a preliminary assessment of likely transmission patterns. In most cases, this is due to the efforts of individual researchers, and is a marked reflection of the strength and priority given to clinical and entomological research in each country. Those such as Argentina, Brazil and Venezuela, with a strong tradition and committment to investment in research, were the first to make this tran- 
sition largely because they had the trained and motivated personnel to make the studies to reveal the importance of this disease. Additionally, many of those researchers were to play a role in the political activities of their countries, stimulating further research, refinement of epidemiological data, and eventually, action.

\section{Stage 1. Initial activity}

The first stage towards Chagas disease control derives from recognition that the disease exists, that transmission occurs, and that steps can be taken at a national level to ameliorate the individual and community impact of the infection. Research is more coordinated, with government backing, and becomes focused on studies to determine distribution and prevalence of transmission, with control trials leading to recommendations for intervention and surveillance. In most Latin American countries, it is the clinicians who take the lead, so that the earliest interventions tend to be related to treatment of acute cases and serological screening of blood donors. This is a way of gaining useful epidemiological data as well as impacting the unacceptability of transfusional transmission of T. cruzi. It has been strongly promoted by the Pan American Health Organisation through the 'safe blood initiative' and provides for an improved system of screening for other transfusable infections such as HIV, syphilis and hepatitis.

Countries currently at this initial stage are Mexico, Panama, Ecuador, Suriname, and French Guiana, and the Northern departments of Peru.

\section{Stage 2. Elimination of domestic transmission}

One of the results of the stage 1 activities is a determination of the presence of domestic cycles of T. cruzi transmission resulting from the presence of domestic populations of Triatominae. Such infestations are now medically and morally unacceptable, simply because of the technical feasibility of eliminating them. Domestic Triatominae pose a risk for $T$. cruzi transmission, but they also contribute to chronic iron-deficiency anaemia due to chronic blood-loss, as well as unnecessary stress to the householders. They can readily be eliminated by a professionally applied treatment with modern pyrethroids. Moreover, some domestic populations now appear to be biologically divorced from their putative silvatic ancestors, making them feasible canditates for local eradication. Examples include domestic $T$. infestans throughout the Southern Cone countries, $R$. prolixus in Central America (and probably also in central Colombia), $R$. ecuadoriensis in Northern Peru, and $T$. dimidiata in Ecuador. In other regions, domestic transmission of $T$. cruzi reflects domestic infestation with triatomine species that retain biological links with their silvatic origins. Examples include T. brasiliensis in Northeastern Brasil, and various species of the phyllosoma and protracta complexes in Mexico. Such populations can also be eliminated, but require more consistent surveillance and selective retreatment to prevent re-establishment of the domestic populations.

The technical and operational procedures for elimination of domestic triatomine populations are now well proven and demonstrably cost-effective, so that there is no longer any technical obstacle to eliminating any and all domestic populations of Triatominae. The operational problems rest with political decisions to organise and implement the control programmes, and to continue them to a sustainable end-point. For imported domestic species such as T. infestans in the Southern Cone countries, or $R$. prolixus in Central America, the stable end-point comes from complete regional eradication. For non-imported species such as T. brasiliensis, the stable endpoint comes from initial elimination of the domestic populations coupled with sustained community-based vigilance and retreatment of any newly detected domestic populations. But conceptually, the two are similar. Domestic populations can be eliminated, and the country or region then passes to stage 3 .

\section{Stage 3. Control of adventitious transmission}

Stage 3 represents those situations where there are no domestic populations of Triatominae, and the technical objective is to prevent their establishment. In other words, silvatic Triatominae are present and many may adapt to colonise human dwellings if permitted to do so. Countries such as Uruguay, Chile, Brazil, Argentina, Paraguay, Bolivia, Nicaragua, El Salvador, Guatemala, Honduras, and the Southern departments of Peru, are embarked on programmes to eliminate domestic infestations, and so may enter our 'stage 3' in due course. Domestic infestations also seem fortuitously absent from countries such as Belize, Costa Rica, Guyana, Suriname, and French Guiana, but in all these countries there is a risk that a local silvatic species may adapt to colonise rural dwellings and so initiate a domestic transmission cycle.

As yet, there is no technical solution to this problem. There is currently no technique that would be acceptable and effective in eliminating silvatic populations of Triatominae. But there is an operational solution, with community-based vigilance supported by selective interventions. Informed and motivated communities can report the finding of Triatominae in or near their houses, so that selective treatment of the domicile can be carried out by local vector control staff. This is applicable to regions where there is a known presence of silvatic vector species that are known to enter houses to form domestic colonies, particularly parts of Northeast Brazil with $T$. brasiliensis and T. pseudomaculata, the cerrado and chaco regions of Brazil, Paraguay, and Argentina with T. sordida group and P. megistus, most of Central America where T. dimidiata is widely distributed, and parts of Mexico where species of the phyllosoma complex are widespread.

\section{Stage 4. The final stage}

The final stage is perhaps the most difficult, when vector-borne transmission becomes rare, and the risk of transfusional transmission has been greatly reduced. With this comes the inevitable tendency to relax surveillance and withdraw resources - as already seen in some of the Southern Cone regions. And this can be followed by a loss of awareness and a loss of operational expertise, bringing a renewed risk of reconstituted transmission but without the benefit of infrastructure and surveillance to detect possible problems. Nevertheless, it is the goal to be achieved by all currently endemic countries. It is based on the idea that at the end-point of Chagas disease control, there will be no more domestic vector infestations, there will be no more chronic infections (due to absence 
of significant transmission over a generation or more), and the risk of transfusional transmission will be too low to warrant routine screening of blood donors. At this stage, there would only be random and rare cases of transmission, resulting in occasional acute cases that should be dealt with at the level of clinical detection and treatment. Such an ideal is predicated on the idea that clinical training in diagnosis and treatment can be strengthened and sustained, and that all communities would have appropriate access to the diagnostic services.

This final stage has been described as the Acapulco Syndrome (Dias \& Schofield, in press). Acapulco is a large and prosperous city on the Pacific coast of central Mexico, that shows the full range of communities from the very poor to the very rich and privileged. Domestic populations of Triatominae are no longer apparent - although they were reported up to 20-25 years ago, at least on the periurban fringes of the city. Nevertheless, vectorborne transmission still occurs, albeit rarely. We deduce that some 'event' may trigger the flight of an adult silvatic bug which may fly through an apartment window. That bug would be hungry, and probably infected with T. cruzi. In the apartment, the bug feeds and may transmit the parasite, but fails to survive to establish a domestic colony. The result can be an acute case of Chagas disease, perhaps in someone living high up in a luxurious apartment block - but there is nothing for the vector control authorities to control. We believe that this may represent the end-point of Chagas disease control, relying on clinical surveillance backed by recognition of the bugs if they can be found, with prompt remedial treatment of the rare acute infections that may occur. If we are right, and the Acapulco syndrome can be reached throughout Latin America, then the need for adequate clinical training and community awareness deserves to be stressed even in those areas where current Chagas disease control activities are meeting well-earned success. Paradoxically perhaps, it may be that the Amazon region will be the proving ground for such a system, where domestic infestations of Triatominae are rare or absent, but adventitious bugs may enter houses and contaminate foodstuffs or beverages leading to a "family microepidemic" of acute Chagas disease (Valente \&Valente 1999, Coura et al. 2002), so that control relies almost entirely on clinical and parasitological diagnosis and prompt treatment.

\section{CONCLUSIONS}

The current feeling amongst those involved with Chagas disease control is one of quiet confidence, albeit tinged with perenniel uncertainty about political continuity for the control interventions. There is little doubt that domestic populations of Chagas disease vectors can be eliminated, and that together with improved screening of blood donors, this will progressively reduce transmission of T. cruzi. And for some of the primary vectors, particularly T. infestans in the Southern Cone and R. prolixus in Central America, it seems likely that once the domestic populations are eliminated they will not be reconstituted - at least not by the same species. For other important vectors such as T. brasiliensis in Northeast Brazil, and T. dimidiata in Central America and the Andean Pact, there is a need to improve methods to control peridomestic populations, but there is some confidence that once the domestic populations have been eliminated then regular community-based vigilance will allow any resurgent domestic populations to be dealt with on a local level. This will involve some strategic and operational modifications within the current concept of decentralised health intervention services, but such modifications have been foreseen, discussed, and are in the process of being implemented.

The present challenges for complete control of human Chagas disease in Latin America consist basically of (1) launching adequate national programmes in those countries where Chagas disease exists but is not yet properly considered by the national health authorities, and (2) improving and maintaining the existing programmes. The launch of new national programmes will be a politcial decision, that must be reinforced by consistent epidemiological data. For the existing programmes, as in Brazil, the current requirements can be summarised as follows (Schofield \& Dias 1999, Dias 2000, Vinhaes 2002): (a) to maintain the political priority of the programme until its consolidation (5-10 years); (b) to improve and refine epidemiological surveillance, that must become more focused at peripheral administrative levels supported by regional and national technical reference groups; (c) to improve and refine methods and strategies for the control of peridomestic infestation by secondary vector species; (d) to cover $100 \%$ of blood transfusions with prior serological selections; (e) to improve medical and social attention to the remaining chagasic individuals.

In spite of dramatic progress over the last decade, there remain three enormous areas endemic for Chagas disease vectors, where Chagas disease surveillance and control is in its infancy - Amazonia, Mexico, and the USA. The Amazon region, comprising much of Brazil, Bolivia, Peru, Colombia, Ecuador, Venezuela and the Guianas, represents a major challenge. Here, human colonisation is associated with major changes in land use, which already present a risk for domestication of otherwise silvatic species of Triatominae. In the Brazilian Amazonia alone, over 300 cases of Chagas disease have been diagnosed in the last 10 years (Coura et al. 2002) together with evidence of progressive domestication of vector species such as $P$. geniculatus, T. maculata, and R. brethesi. In other Amazonian countries, there are increasing reports of silvatic species of Triatominae flying into dwellings, with a similar increase in reports of Chagas disease transmission (eg. Raccurt 1999, Abad-Franch et al. 2001). As these countries of South America gain experience in surveillance and control of Chagas disease vectors, we can hope that this experience will be applied to the Amazon region, leading to an adequate level of entomological surveillance, selective intervention, and research to identify the key features of human colonisation and land use change that can trigger the domestication process in otherwise silvatic species of Triatominae.

Elsewhere, the situation is different. In the USA, Chagas disease vectors are widespread but well-known to the scientific community. And they are species that rarely enter homes except under extreme conditions - for example when drought triggers high mortality of their silvatic reservoir hosts. So vector-borne Chagas disease is rare in the USA. In contrast, blood-borne transmission 
may be increasing, and there is as yet insufficient screening for T. cruzi in USA bloodbanks. In Mexico also, screening for $T$. cruzi infection in blood donors does not have high coverage, and vector-borne transmission is widespread. Data from large-scale serological surveys suggest well over one million cases of T. cruzi infection in Mexico (Guzmán-Bracho 2001), while entomological studies reveal a wide variety of domestic vector populations representing several species of the T. phyllosoma and $T$. protracta complexes, as well as $T$. dimidiata in the southern states. It is to be hoped that Mexico will soon implement an adequate system of vector surveillance and control throughout the country, together with improved screening of blood donors.

But the greatest risk to the current successful trend in Chagas disease control comes, in a sense, from the success that has been achieved. For as Chagas disease becomes less of a public health problem, then the need for continued surveillance and selective intervention becomes less appreciated at the political level. There is a tendency for government and political authorities to deprecate the problem of human Chagas disease and give priority to emergent questions such as dengue fever. In parallel, there is a tendency to decrease scientific and technical interest about Chagas disease and its control, not only in research institutions but also in universities. Even at the industrial level, success in Chagas vector control can lead to declining industrial interest as the market for insecticides and equipment becomes reduced. Decentralization of public health programmes has been an additional problem, mainly because the peripheral administrative levels generally have neither tradition nor expertise to implement vector control interventions, and limited infrastructure to maintain epidemiological surveillance. This problem is apparent in all endemic countries where decentralisation has not been accompanied by formation of strong central core groups able to advise and reinforce peripheral administrations wherever needed. Similar problems remain in the educational levels, which have rarely been adequately developed to maintain community awareness to reinforce participation in entomological and epidemiological surveillance.

If epidemiological vigilance were to be prematurely relaxed, the consequences could be severe due to progressive re-establishment of foci of active transmission. Such a scenario was indeed contemplated during the initial planning of the Southern Cone Initiative, by considering the alternative strategy of intervention without subsequent vigilance. The analysis showed that although premature curtailment of active surveillance would reduce overall programme costs by around $5.4 \%$, the total benefits accruing to the programme would decline by $33 \%$, reaching zero after 11 years (Fig. 3) (Dias \& Schofield 1991, Akhavan 2000). Such estimates give an important warning, and we emphasise again the need to ensure continuity of surveillance and intervention at the political level, and at the community level where it is already apparent that many communities have lost awareness of the triatomine bugs that they have not seen for some decades, and at the clinical level to ensure adequate continuity of medical training so that future infections will not go undetected.
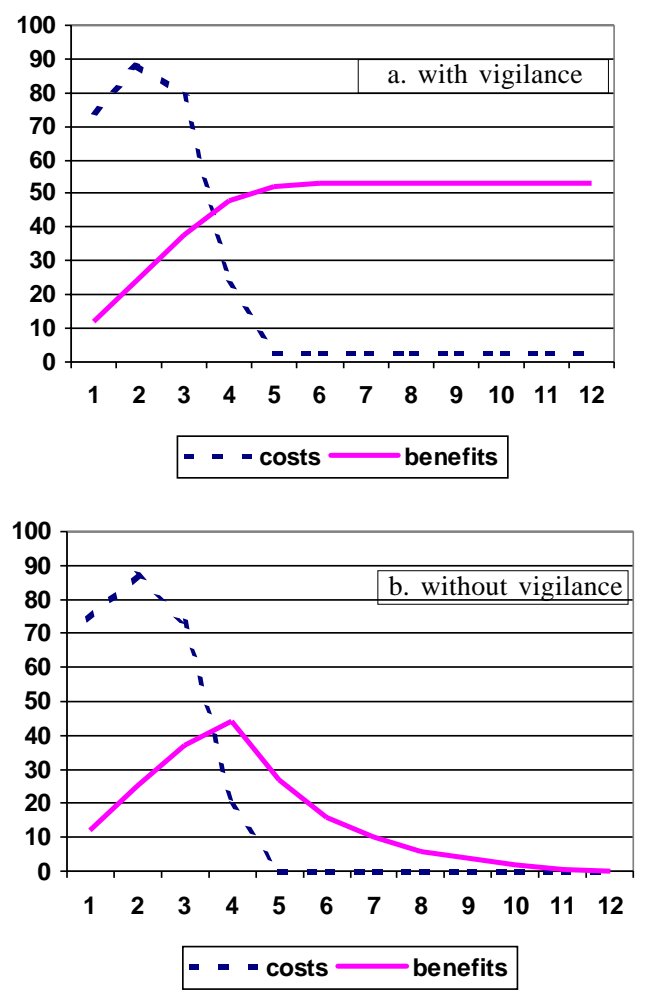

Fig. 3: analysis of costs and benefits of Chagas disease vector control for the Southern Cone region, assuming (a) initial attack phase followed by continued annual vigilance, or (b) initial attack phase with no subsequent vigilance. With vigilance, costs sum over 12 years to approximately US $\$ 350$ million, with annual benefits rising to a continuous plateau of just over US\$53 million per year. Without vigilance, total intervention costs are reduced by $5.4 \%$, but benefits are reduced by $33 \%$ and decline to zero after 11 years (modified from Schofield \& Dias 1991, and Akhavan 2000).

\section{REFERENCES}

Abad-Franch F, Paucar CA, Carpio CC, Cuba Cuba CA, Aguilar VHM, Miles MA 2001. Biogeography of Triatominae in Ecuador: implications for the design of control strategies. Mem Inst Oswaldo Cruz 96: 611-620.

Acevedo F, Godoy E, Schofield CJ 2000. Comparison of intervention strategies for control of Triatoma dimidiata in Nicaragua. Mem Inst Oswaldo Cruz 95: 867-871.

Akhavan D 2000. Análise de Custo-efetividade do Programa de Controle da Doença de Chagas no Brasil, Organização Pan-Americana da Saúde, Brasília, 271 pp.

Basombrio MA, Schofield CJ, Rojas CL, Del Rey EC 1998. A cost-benefit analysis of Chagas disease control in Northwest Argentina. Trans R Soc Trop Med Hyg 92: 137-143.

Bittencourt AL 2000. Transmissão vertical da doença de Chagas. Rev Patol Trop 29 (Supl.): 101-115.

Briceño-León R 1990. La Casa Enferma. Sociologia de la Enfermedad de Chagas, Ediciones Capriles, Caracas, 153 pp.

Briceño-León R 1993. La enfermedad de Chagas: una construcción social. In R Briceño-León, JCP Dias (eds), Las Enfermedades Tropicales en la Sociedad Con-temporanea, Acta Científica de Venezuela, Caracas, p. 257-282.

Coura JR, Junqueira ACV, Fernandes O, Valente SAS, Miles MA 2002. Emerging Chagas disease in Amazonian Brasil. Trends Parasitol 18: 171-176.

Dias E 1962. Os efeitos da superinfecção sobre a evolução da cardiopatia crônica chagásica. Rev Goiana Med 9 (Supl.): 233-239. 
Dias E, Pellegrino J 1948. Alguns ensaios com o "Gammexane" no combate aos transmissores da doença de Chagas. BrasilMédico 62: 185-191.

Dias JCP 1982. Doença de Chagas em Bambuí, Minas Gerais, Brasil. Estudo Clínico-epidemiológico a Partir da Fase Aguda, entre 1940 e 1982, Thesis, Universidade Federal de Minas Gerais, Belo Horizonte, 375 pp.

Dias JCP 1987. Control of Chagas disease in Brazil. Parasitol Today 3: 336-341.

Dias JCP 2000. Chagas disease control and the natural history of human Chagas disease: a possible interaction? Mem Inst Oswaldo Cruz 95 (Suppl. II): 14-20.

Dias JCP, Coura JR 1997. Epidemiologia. In JCP Dias, JR Coura (eds), Clínica e Terapêutica da Doença de Chagas: uma Abordagem Prática para o Clínico Geral, Fiocruz, Rio de Janeiro, p. 33-66.

Dias JCP, Schofield CJ 1998. Controle da transmissão transfusional da doença de Chagas na Iniciativa do Cone Sul. Rev Soc Bras Med Trop 31: 373-383.

Dias JCP, Schofield CJ 1999. The evolution of Chagas disease (American trypanosomiasis) control after 90 years since Carlos Chagas discovery. Mem Inst Oswaldo Cruz 94 (Suppl. I): 103-121.

Dias JCP, Schofield CJ 2002. Control of Triatominae. In I Maudlin, P Holmes, MA Miles (eds), Trypanosomiases (in press).

Dujardin JP, Bermudez H, Schofield CJ 1997a. The use of morphometrics in entomological surveillance of silvatic foci of Triatoma infestans in Bolivia. Acta Trop 66: 145-153.

Dujardin JP, Bermudez H, Casini C, Schofield CJ, Tibayrenc M 1997b. Metric differences between silvatic and domestic Triatoma infestans (Hemiptera: Reduviidae) in Bolivia. $J$ Med Entomol 34: 544-551.

Dujardin JP, Cardozo L, Schofield CJ 1996. Genetic analysis of Triatoma infestans following insecticidal control interventions in central Bolivia. Acta Trop 61: 263-266.

Dujardin JP, Muñoz M, Chavez T, Ponce C, Moreno J, Schofield CJ 1998b. The origin of Rhodnius prolixus in Central America. Med Vet Entomol 12: 113-115.

Dujardin JP, Schofield CJ, Tibayrenc M 1998a. Population structure of Andean Triatoma infestans: allozyme frequencies and their epidemiological relevance. Med Vet Entomol 12: 20-29.

Guzmán-Bracho C 2001. Epidemiology of Chagas disease in Mexico: an update. Trends Parasitol 17: 372-376.

Kabayo J 2002. Tsetse kills. Can Africa deal with it? Trends Parasitol 18 (in press).

Keng-Hong T 2000. Area-wide Control of Fruit Flies and other Insect Pests, Penerbit Universiti Sains Malaysia, Penang, 782 pp.

Macedo VO 1976. Influência da exposição à reinfecção na evolução da doença de Chagas. Estudo longitudinal de 5 anos. Rev Patol Trop 5: 33-115.

Marcilla A, Bargues MD, Ramsey JM, Magallon E, SalazarSchettino PM, Abad-Franch F, Dujardin JP, Schofield CJ, Mas-Coma S 2001. The ITS-2 rDNA as a molecular marker for populations, species and phylogenetic relationships in Triatominae (Hemiptera: Reduviidae), vectors of Chagas disease. Mol Phylog Evol 18: 136-142.

Meggers BJ, Evans C 1963. Aboriginal Cultural Development in Latin America: an Interpretaive Review, Vol. 146, Smithsonian Miscellaneous Collections, Washington, 148 pp.

Moraes-Souza H 2000. Transmissão transfusional da doença de Chagas. Rev Patol Trop 29 (Supl.): 91-100.

Moya P, Moretti E 1997. Doença de Chagas congênita. In JCP Dias, JR Coura (eds), Clínica e Terapêutica da Doença de Chagas: uma Abordagem Prática para o Clínico Geral, Fiocruz, Rio de Janeiro, p. 383-410.

Raccurt C 1999. Acute chagasic cardiopathy in French Guiana: a re-emergent hazard linked to ecological change? Ann Trop
Med Parasitol 93: 183-184.

Ramsey JM, Cruz-Celis A, Salgado L, Alvear AL, Espinosa L, Ordoñez R, Salgado-Albarran L, Schofield CJ 2000. Field trial of pyrethroid insecticides against domestic and peridomestic populations of Triatoma pallidipennis and Triatoma barberi in Mexico. XV International Congress for Tropical Medicine and Malaria, Cartagena de Indias, Colombia.

Romaña C, Abalos JW 1948. Acción del "Gammexane" sobre los triatomideos. "Control" domiciliario. An Inst Med Regional, Tucuman 2: 95-106.

Ruiz H 1953. Rhodnius prolixus in Costa Rica. Rev Biol Trop 1: 239-240.

Schmunis GA 1999a. Iniciativa del Cono Sur. Proceedings of the II International Workshop on Population Genetics and Control of Triatominae, Tegucigalpa, Honduras, p. 26-31.

Schmunis GA 1999b. A tripanossomíase americana e seu impacto na Saúde Pública das Américas. In Z Brener, ZA Andrade, M Barral Netto (eds), Trypanosoma cruzi e Doença de Chagas, 2a. ed., Guanabara-Koogan, Rio de Janeiro, p. 1-15.

Schmunis GA, Zicker F, Cruz JR, Cuchi P 2001. Safety of blood supply for infectious diseases in Latin American countries. Am J Trop Med Hyg 65: 924-930.

Schofield CJ 1988. Biosystematics of the Triatominae. In MW Service, Biosystematics of Haematophagous Insects, Clarendon Press, Oxford, p. 284-312.

Schofield CJ 2002. Evolution and control of Triatoma dimidiata. Taller para el establecimiento de pautas tecnicas en el control de Triatoma dimidiata, OPS, El Salvador (in press).

Schofield CJ, Dias JCP 1991. A cost-benefit analysis of Chagas disease control. Mem Inst Oswaldo Cruz 86: 285-295.

Schofield CJ, Dias JCP 1999. The Southern Cone Initiative against Chagas disease. Adv Parasitol 42: 1-27.

Schofield CJ, Dujardin JP 1997. Chagas disease vector control in Central America. Parasitol Today 13: 141-144.

Schofield CJ, Dujardin JP 1999. Theories on the evolution of Rhodnius. Actualidades Biol (Medellin) 70: 183-197.

Schofield CJ, Maudlin I 2001. Trypanosomiasis control. Int J Parasitol 31: 615-620.

Solis-Mena S, Patterson JS, Abad-Franch F 2000. Studying the origin of Ecuadorian Triatoma dimidiata populations (Hemiptera: Reduviidae: Triatominae). TDR/Wellcome Trust/ ECLAT Workshop on Trypanosomatid Evolution, London, poster.

Souza AG, Wanderley DMV, Buralli GM, Andrade JCR, 1984. Consolidation of the control of Chagas disease vectors in the State of São Paulo. Mem Inst Oswaldo Cruz 79 (Suppl.): 125-132.

Valente SAS, Valente V da C 1999. Epidemiologia e transmissão da doença de Chagas na Amazônia Brasileira. Proceedings of the II International Workshop on Population Genetics and Control of Triatominae, Tegucigalpa, Honduras, p. 101-104.

Vinhaes MC 2002. The situation of Southern Cone Initiative. Presentation at the XI Meeting of the Intergovernmental Comission of the Southern Cone Initiative for the elimination of Triatoma infestans and the control of transfusion transmission of Chagas disease, Asunción, Paraguay.

Wendell S 1997. Doença de Chagas transfusional. In JCP Dias, JR Coura (eds), Clínica e Terapêutica da Doença de Chagas: uma Abordagem Prática para o Clínico Geral, Fiocruz, Rio de Janeiro, p. 411-427.

World Bank 1993. World Development Report 1993. Investing in Health. Oxford University Press, New York, 329 pp.

WHO-World Health Organization 1991. Control of Chagas disease, Technical Repport Series, 811. Geneva, 91 pp.

WHO-World Health Organization 1998. Eliminación de la transmisión de la enfermedad de Chagas. $51^{\text {a }}$ Asamblea Mundial de la Salud, Doc. WHA51.14, 2 pp. 